\title{
Sann-Joong-Kuey-Jian-Tang decreases the protein expression of mammalian target of rapamycin but increases microtubule associated protein II light chain 3 expression to inhibit human BxPC-3 pancreatic carcinoma cells
}

\author{
CHIN-CHENG SU ${ }^{1-4}$ \\ ${ }^{1}$ Tumor Research Center of Integrative Medicine; ${ }^{2}$ Comprehensive Breast Cancer Center; ${ }^{3}$ Department of Surgery, \\ Changhua Christian Hospital, Changhua, Taiwan 50006; ${ }^{4}$ School of Chinese Medicine, College of \\ Chinese Medicine, China Medical University, Taichung, Taiwan 40651, R.O.C.
}

Received February 18, 2014; Accepted November 19, 2014

DOI: $10.3892 / \mathrm{mmr} .2014 .3090$

\begin{abstract}
Sann-Joong-Kuey-Jian-Tang (SJKJT), a Traditional Chinese Medicinal prescription, has been used for the treatment of lymphadenopathy and solid tumors, and has shown therapeutic potential in a number of human malignant tumor cell lines, such as Hep-G2 hepatocellular carcinoma cells. Previous mechanistic studies demonstrated that SJKJT inhibited the proliferation of BxPC-3 pancreatic carcinoma cells through the extrinsic and intrinsic apoptotic pathways in vitro. SJKJT was also shown to be cytotoxic to colo 205 colon cancer cells by inducing autophagy in vitro. The present study therefore investigated molecular mechanisms of autophagy in human BxPC-3 pancreatic cancer cells treated with SJKJT. The cytotoxic effects of SJKJT on BxPC-3 human pancreatic carcinoma cells were evaluated using an MTT assay. Furthermore, the expression of autophagy-associated proteins, including mammalian target of rapamycin (mTOR), beclin-1, autophagocytosis-associated protein (Atg)3, Atg7, Atg5-Atg12 and microtubule-associated protein II light chain 3 (LC3-II), was assessed using western blot analysis. The results demonstrated that BxPC-3 cells treated with SJKJT exhibited decreased expression levels of mTOR and increased expression of LC3-II protein. In addition, the expression of the beclin-1, Atg3, Atg7 and Atg5-Atg12 proteins was increased during the first $24 \mathrm{~h}$, but decreased from 48 to $72 \mathrm{~h}$. The results showed that SJKJT inhibited the proliferation of human BxPC-3 pancreatic cancer
\end{abstract}

Correspondence to: Dr Chin-Cheng Su, Tumor Research Center of Integrative Medicine, Changhua Christian Hospital, 135 Nan-Hsiao Street, Changhua, Taiwan 50006, R.O.C.

E-mail: succ.maeva@msa.hinet.net

Key words: Sann-Joong-Kuey-Jian-Tang, mammalian target of rapamycin, microtubule associated protein II light chain 3, autophagy, human pancreatic carcinoma BxPC-3 cells cells in vitro. A possible underlying molecular mechanism may be the induction of autophagy. Further investigation into the therapeutic potential of SJKJT in human pancreatic cancer is required.

\section{Introduction}

Sann-Joong-Kuey-Jian-Tang (SJKJT), a Traditional Chinese Medicinal preparation, has been prescribed as a complementary medicine for patients with solid tumors in Taiwan. It consists of 17 species of medicinal herbs: Curcuma aeruginosa Roxb., Laminaria japonica Aresch, Bupleurum scorzonerifolium Willd (Bupleurum chinense DC), Coptis chinensis Franch, Paeonia lactiflora Pall, Pueraria lobata Ohwi, Trichosanthes cucumeroides Maxim, Phellodendron amurense Rupr., Glycyrrhiza uralensis Fisch, Sparganium stoloniferum Buch., Anemarrhena asphodeloides Bunge, Angelica sinensis Diels, Cimicifuga heracleifolia Komar, Scutellaria baicalensis Georgi, Gentiana scabra Bunge, Platycodon grandiflorus and Forsythia suspensa Vahl. It has been shown that SJKJT does not exert significant toxic effects on certain types of normal cells (1). A previous study by our group demonstrated that SJKJT increased the protein expression levels of tumor necrosis factor- $\alpha$ (TNF- $\alpha$ ), caspase- 8 and caspase- 3 in colo 205 colon cancer cells, thereby inducing apoptosis in vivo and in vitro (2). It was also shown that SJKJT inhibited the proliferation of Hep-G2 hepatocellular carcinoma cells by increasing the expression of TNF- $\alpha$, caspase- 8 , caspase-3 and B-cell lymphoma 2 (Bcl-2)-associated X (Bax) and decreasing that of translationally controlled tumor protein (TCTP) and myeloid cell leukemia 1 protein (Mcl-1) in vitro (3). Delayed diagnosis and a poor response to current forms of chemotherapy render pancreatic cancer a challenging malignancy to treat and the fourth leading cause of cancer-associated mortality in the USA $(4,5)$. These statistics indicate that the development of novel therapeutic agents is required. Mujumdar et al (6) demonstrated that triptolide kills pancreatic cancer cells via two different mechanisms. It 


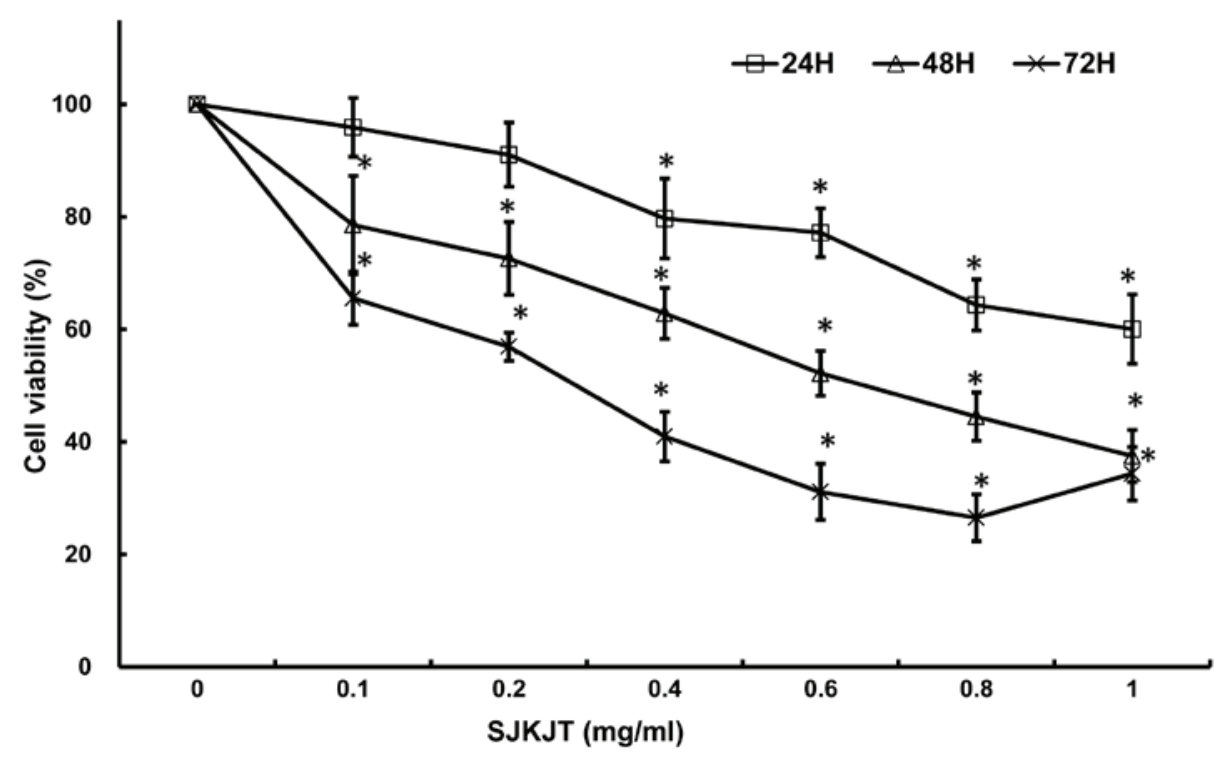

Figure 1. Cytotoxicity of SJKJT on BxPC-3 cells. The cytotoxicity of SJKJT was determined using the MTT assay. Values are presented as the mean \pm standard deviation of three experiments. "P<0.05 vs. 0 mg/ml SJKJT. SJKJT, Sann-Joong-Kuey-Jian-Tang.

induces caspase-dependent apoptotic death in human BxPC-3 pancreatic cancer cells and caspase-independent autophagic death in metastatic cell lines. Traditional Chinese Medicinal herbs are increasingly recognized as having the potential for development as alternative therapies for a number of human malignant tumors (7). Previous studies have also shown that SJKJT inhibits the proliferation of human BxPC-3 pancreatic cancer cells by decreasing the expression of TCTP and Mcl-1 expression and increasing that of $\mathrm{TNF}-\alpha$ and $\mathrm{Bax}$ in vitro (8). SJKJT is a potential chemotherapeutic agent for use in pancreatic cancer. The anticancer effects of SJKJT on human pancreatic cancer have not yet been fully elucidated, and therefore, further studies are required to investigate the mechanisms of action underlying its effects. Autophagy, derived from auto (self) and phagy (to eat), refers to self-digestion as a means of providing an alternative energy source. When cellular stress leads to continuous or excessive induction of autophagy, cell death may ensue. Thus, cell survival or cell death depends on the duration and severity of the insult (9). It has been shown that autophagy is activated in pancreatic cancer cells and is correlated with a poor patient outcome (10). It has also been demonstrated that pancreatic cancer requires autophagy for tumor growth (11). Previous studies have shown that SJKJT inhibits the proliferation of human colo 205 colon cancer cells by increasing the expression of the microtubule-associated protein II light chain 3 (LC3-II) protein in vitro (12). The present study focused on the mechanisms underlying the induction of autophagy by SJKJT in human BxPC-3 pancreatic cancer cells.

\section{Materials and methods}

Cells and reagents. The $\mathrm{BxPC}-3$ human pancreatic cancer cell line (BCRC number: 60283) was obtained from the American Type Culture Collection (ATCC no. CRL-1687; Passage no. 9; mycoplasmic, negative; Manassas, VA, USA). The crude extract of SJKJT was obtained from Chuang Song
Zong Pharmaceutical Co., Ltd. (Ligang Plant, Taiwan). Fetal bovine serum (FBS) and glutamine were obtained from Gibco BRL (Invitrogen Life Technologies, Grand Island, NY, USA). MTT, sodium deoxycholate, leupeptin, Triton X-100, Tris- $\mathrm{HCl}$, ribonuclease-A, sodium pyruvate, 4-(2-hydroxyethyl)-1-piperazineethanesulfonic acid (HEPES), dimethyl sulfoxide (DMSO) and RPMI-1640 were obtained from Sigma-Aldrich (St. Louis, MO, USA). Potassium phosphates and Tris-EDTA (TE) buffer were purchased from Merck Millipore (Darmstadt, Germany). BioMax film was obtained from Kodak (Rochester, NY, USA). The following antibodies were used: Monoclonal insulin-like growth factor 1 receptor (IGFR; no. 3018, MW $95 \mathrm{kDa}$ ), monoclonal protein kinase B (AKT; no. 3063S, MW 60 kDa), monoclonal mammalian target of rapamycin (mTOR; no. 2983, MW 289 kDa), polyclonal beclin-1 (no. 3738, MW: $60 \mathrm{kDa}$ ) and polyclonal LC3-II (no. 3775, MW 14, $16 \mathrm{kDa}$ ) were obtained from Cell Signaling Technology, Inc. (Danvers, MA, USA); monoclonal Caspase-3 (Novus, Lot: NB500-210), monoclonal autophagocytosis associated protein (Atg) 7 (GTX63486, MW: $78 \mathrm{kDa}$ ), monoclonal Atg 3 (GTX63041, MW: $40 \mathrm{kDa}$ ), monoclonal Atg5-Atg12 (GTX62601, MW: 55 kDa); mouse anti- $\beta$-actin. The antibodies were diluted in 5\% nonfat dry milk, $1 \mathrm{X}$ Tris-buffered saline and $0.1 \%$ Tween-20 (Sigma-Aldrich) at $4^{\circ} \mathrm{C}$ with gentle shaking, overnight. Penicillin-streptomycin was obtained from Sigma-Aldrich.

Cell culture. The BxPC-3 cells were maintained in RPMI-1640 medium containing $10 \% \mathrm{FBS}, 1 \%$ penicillin/streptomycin (10,000 U/ml penicillin, $10 \mathrm{mg} / \mathrm{ml}$ streptomycin) at $37^{\circ} \mathrm{C}$ in a humidified atmosphere containing $5 \% \mathrm{CO}_{2}$.

Cytotoxicity of SJKJT in BxPC-3 cells. The BxPC-3 cells were plated in 96-well plates at a density of $1 \times 10^{4}$ cells per well for 16-20 $\mathrm{h}$ and then treated with various concentrations of SJKJT $(0,0.1,0.2,0.4,0.6,0.8$ and $1 \mathrm{mg} / \mathrm{ml})$ for different durations (24, 48 and 72 h). Subsequently, the cells were incubated with $1 \mathrm{mg} / \mathrm{ml}$ of MTT in fresh RPMI medium for $2 \mathrm{~h}$. The surviving 

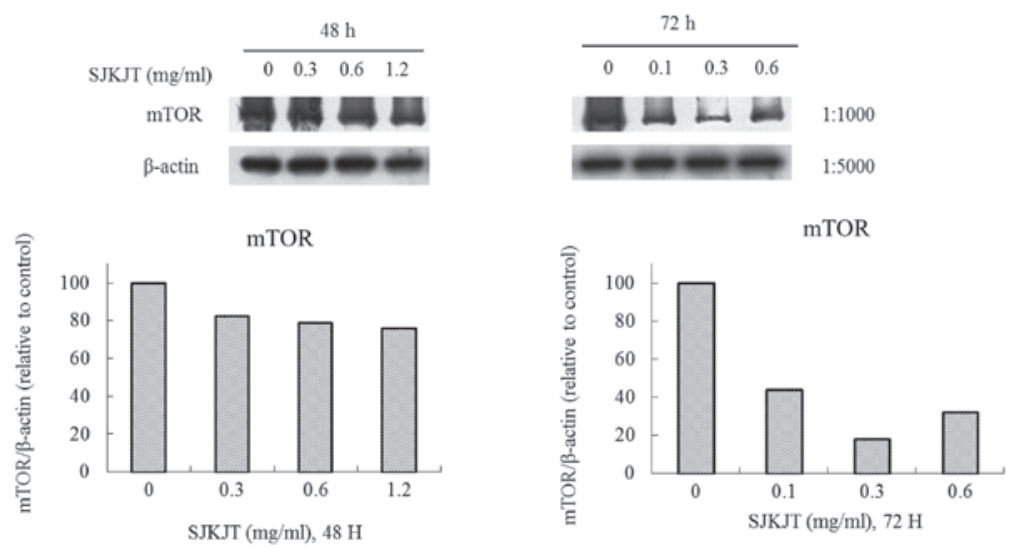

Figure 2. Protein expression of mTOR in BxPC- 3 cells. The BxPC- 3 cells were treated with various concentrations of SJKJT for different durations $(0,0.3$, 0.6 and $1.2 \mathrm{mg} / \mathrm{ml}$ for $48 \mathrm{~h}$; and $0,0.1,0.3$ and $0.6 \mathrm{mg} / \mathrm{ml}$ for $72 \mathrm{~h}$ ). Expression of the mTOR protein was then evaluated by western blot analysis. Following treatment of BxPC-3 cells with various concentrations of SJKJT for 48 or $72 \mathrm{~h}$, the expression of the mTOR protein was decreased in a dose-dependent manner. mTOR, mammalian target of rapamycin; SJKJT, Sann-Joong-Kuey-Jian-Tang.
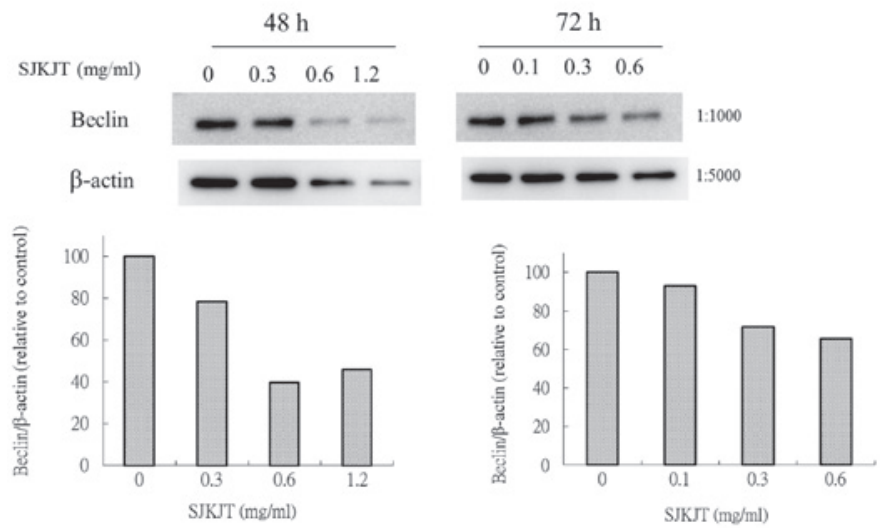

Figure 3. Expression of the beclin-1 protein in BxPC-3 cells. BxPC-3 cells were treated with various concentrations of SJKJT for different durations $(0,0.3,0.6$ and $1.2 \mathrm{mg} / \mathrm{ml}$ for $48 \mathrm{~h} ; 0,0.1,0.3$ and $0.6 \mathrm{mg} / \mathrm{ml}$ for $72 \mathrm{~h}$ ). Expression of the beclin-1 protein was then evaluated by western blot analysis. Following treatment of BxPC-3 cells with various concentrations of SJKJT for 48 or $72 \mathrm{~h}$, the expression of the beclin-1 protein decreased in a dose-dependent manner. SJKJT, Sann-Joong-Kuey-Jian-Tang.

cells were measured at $590 \mathrm{~nm}$ using a microplate reader. The relative percentage of cell viability was calculated by dividing the absorbance of treated cells by that of the control in each experiment using the following formula: Proliferation rate $(\%)=\left(\mathrm{OD}_{\text {test }}-\mathrm{OD}_{\text {blank }}\right) \times 100$, where $\mathrm{OD}_{\text {test }}$ and $\mathrm{OD}_{\text {blank }}$ are the optical density of the test substances and the blank control, respectively.

Western blot analysis. The effects of SJKJT on the protein expression of mTOR, beclin-1, Atg7, Atg3, Atg5-12 and LC3-II in BxPC-3 cells were assessed using western blot analysis. BxPC- 3 cells were treated with various concentrations $(0,0.3$, 0.6 and $1.2 \mathrm{mg} / \mathrm{ml}$ ) of SJKJT for 48 or $72 \mathrm{~h}$ and the protein levels of mTOR, beclin-1, Atg7, Atg3, Atg5-12 and LC3-II were evaluated. BxPC-3 cells were also treated with SJKJT $(0.6 \mathrm{mg} / \mathrm{ml})$ for different durations $(0,12,24,36,48$ and $72 \mathrm{~h})$ and the protein levels of mTOR, beclin-1, Atg7, Atg3, Atg5-12 and LC3-II were evaluated by western blot analysis.

Following treatment with SJKJT, cells were lysed in ice-cold whole cell extract buffer containing protease inhibitors (BioVision, Inc., Milpitas, CA, USA). The lysate was agitated for $30 \mathrm{~min}$ at $4^{\circ} \mathrm{C}$ and centrifuged at 7,267 $\mathrm{x} \mathrm{g}$ for 10 min. Protein concentration was measured using a bicinchoninic acid protein assay kit (Pierce Biotechnology, Inc., Rockford, IL, USA). Equal quantities of protein were subjected to electrophoresis using $12 \%$ SDS-PAGE. To ensure equal protein loading and transfer, proteins were then transferred onto polyvinylidene difluoride membranes and the membranes were blocked overnight at $4^{\circ} \mathrm{C}$ using blocking buffer $(5 \%$ non-fat dried milk in solution containing $50 \mathrm{mM}$ Tris/ $\mathrm{HCl}, \mathrm{pH} 8.0$; $2 \mathrm{mM} \mathrm{CaCl}_{2} ; 80 \mathrm{mM}$ sodium chloride; $0.05 \%$ Tween 20 ; and $0.02 \%$ sodium azide). Membranes were then incubated for $2 \mathrm{~h}$ at $25^{\circ} \mathrm{C}$ with the primary antibodies listed above, followed by anti-rabbit or anti-mouse immunoglobulin G-horseradish peroxidase-conjugated secondary antibodies. The membranes were washed three times for $10 \mathrm{~min}$ with washing solution. Finally, the protein bands were visualized on an X-ray film using the K-12045-D50 WesternBright ${ }^{\mathrm{TM}}$ enhanced chemiluminescence kit (Advansta, Inc., Menlo Park, CA, USA) and quantified using Image J software, version 1.44 (National Institute of Health, Bethesda, MD, USA) The reference proteins GAPDH and $\beta$-actin were used as internal control. 
$\mathbf{A}$

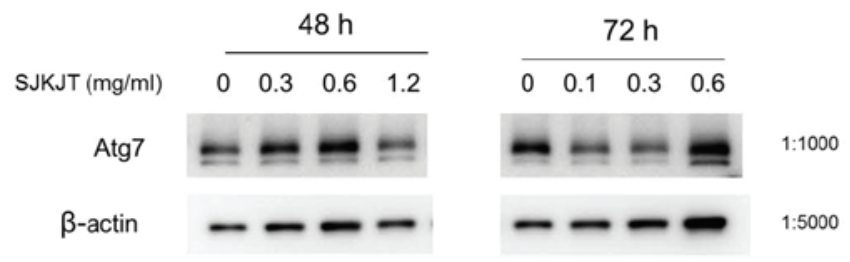

Atg7

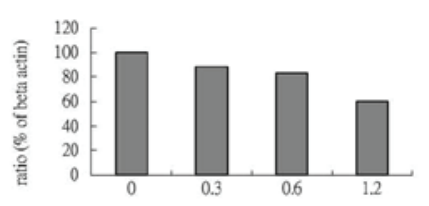

$\mathrm{SJKJT}(\mathrm{m} / \mathrm{ml}), 48 \mathrm{H}$

B
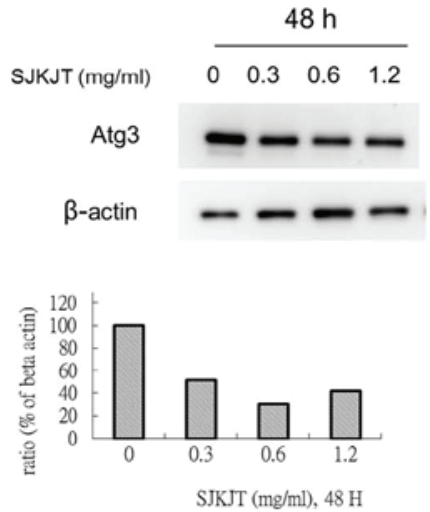

C

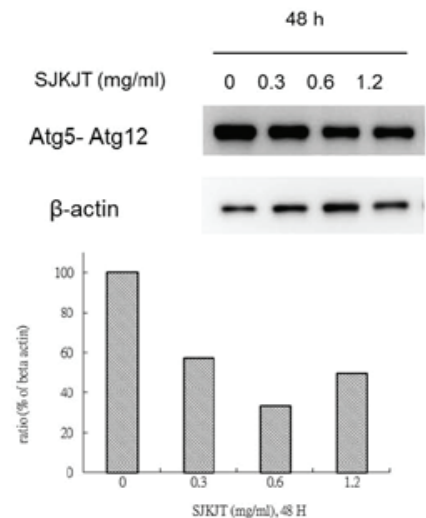

Atg7

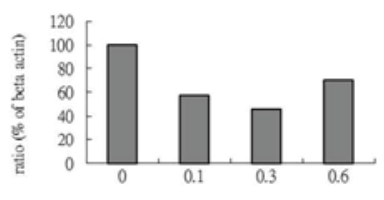

$\operatorname{SJKTT}(\mathrm{mg} / \mathrm{ml}), 72 \mathrm{H}$

$\begin{array}{llll}0 & 0.1 & 0.3 & 0.6\end{array}$
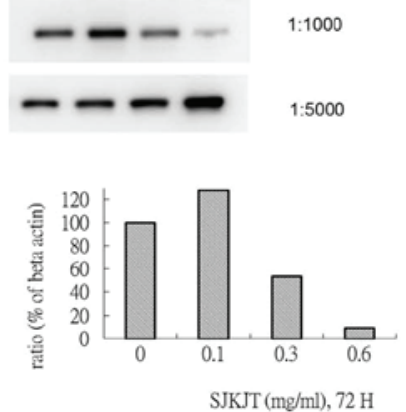

Figure 4. Protein expression of Atg7, Atg3 and Atg5-Atg12 in BxPC-3 cells. BxPC-3 cells were treated with various concentrations of SJKJT for different durations $(0,0.3,0.6$ and $1.2 \mathrm{mg} / \mathrm{ml}$ for $48 \mathrm{~h} ; 0,0.1,0.3$ and $06 \mathrm{mg} / \mathrm{ml}$ for $72 \mathrm{~h})$. Expression of these proteins was then evaluated by western blot analysis. Following treatment of BxPC-3 cells with various concentrations of SJKJT for 48 or 72 h, the expression of (A) Atg-7, (B) Atg-3 and (C) Atg5-Atg12 were reduced in a dose-dependent manner. Atg, autophagocytosis-associated protein; SJKJT, Sann-Joong-Kuey-Jian-Tang.
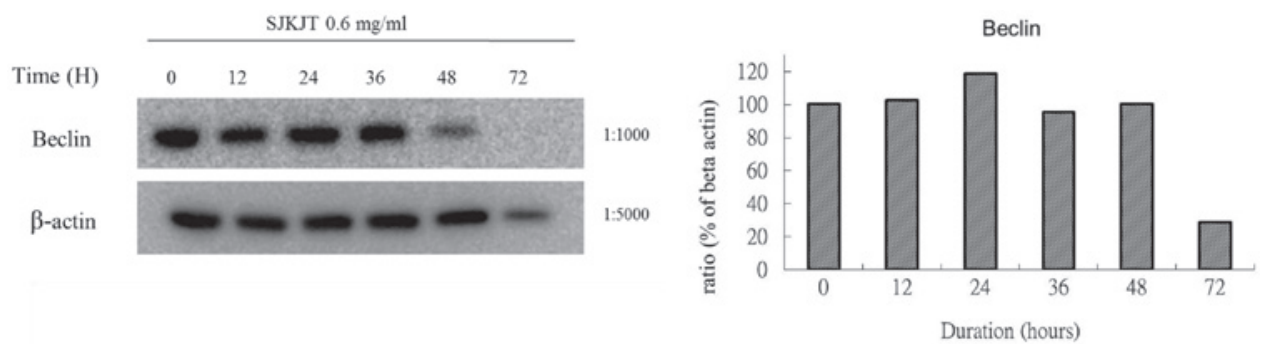

Figure 5. Protein expression of beclin-1 in BxPC-3 cells. BxPC-3 cells were treated with SJKJT $(0.6 \mathrm{mg} / \mathrm{ml})$ for different durations $(0,12,24,36,48$ and 72 h). Expression of the beclin-1 protein was evaluated by western blot analysis. When BxPC-3 cells were treated with SJKJT for different durations, the expression of the beclin-1 protein increased during the first 24 h, but decreased from 48 to 72 h. SJKJT, Sann-Joong-Kuey-Jian-Tang. 
A
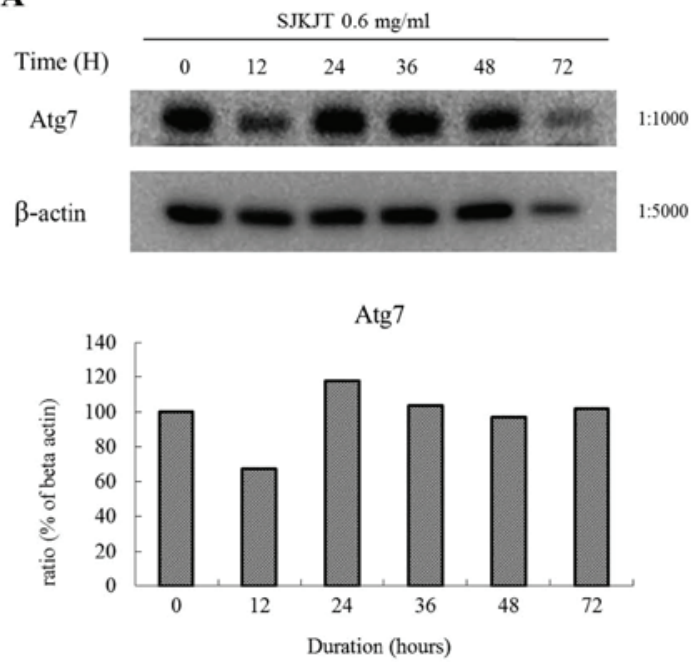

B
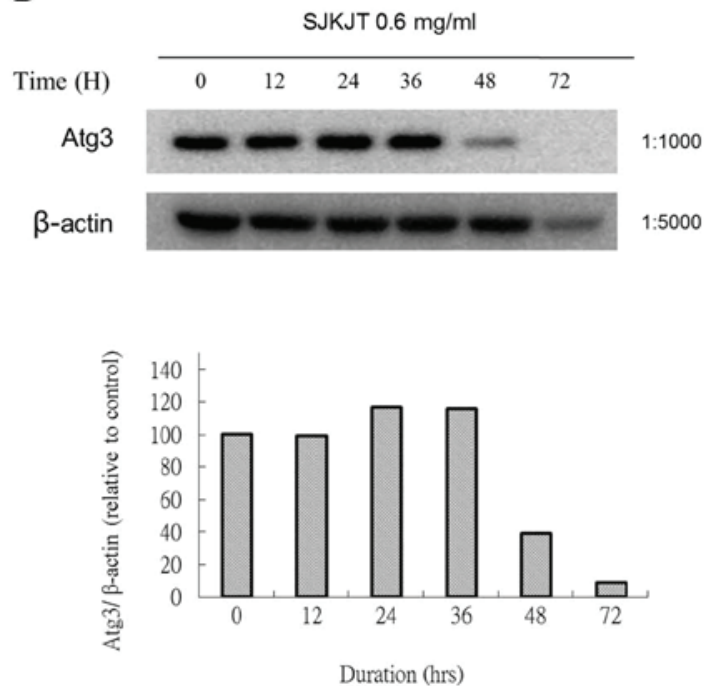

C
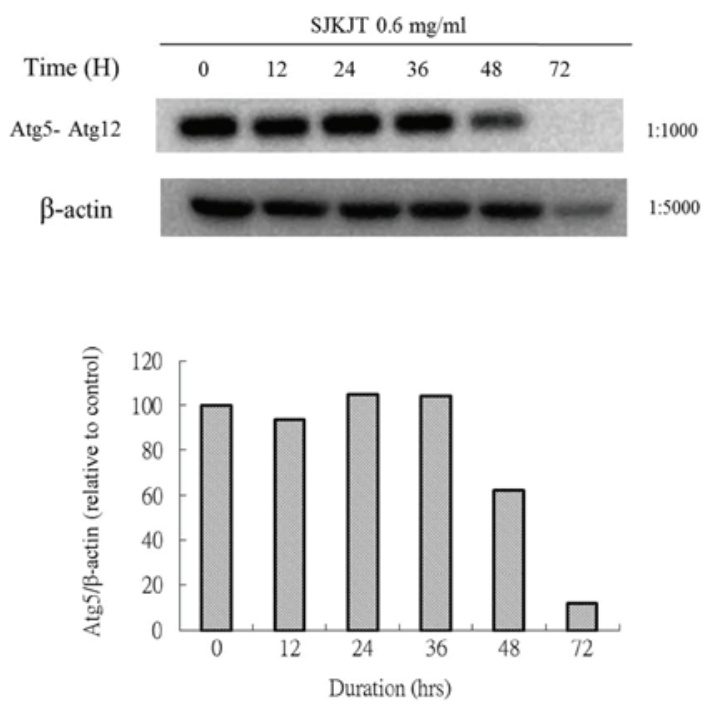

Figure 6. Protein expression of (A) Atg7, (B) Atg3 and (C) Atg5-Atg12 in BxPC-3 cells. BxPC-3 cells were treated with SJKJT $(0.6 \mathrm{mg} / \mathrm{ml})$ for different durations $(0,12,24,36,48$ and $72 \mathrm{~h})$. Expression of the proteins was evaluated by western blot analysis. When BxPC-3 cells were treated with SJKJT for different durations, the expression of the Atg7, Atg3 and Atg5-Atg12 proteins increased during the first $24 \mathrm{~h}$, but that of Atg3 and Atg5-Atg12 decreased at 48 to $72 \mathrm{~h}$. Atg, autophagocytosis associated protein; SJKJT, Sann-Joong-Kuey-Jian-Tang.
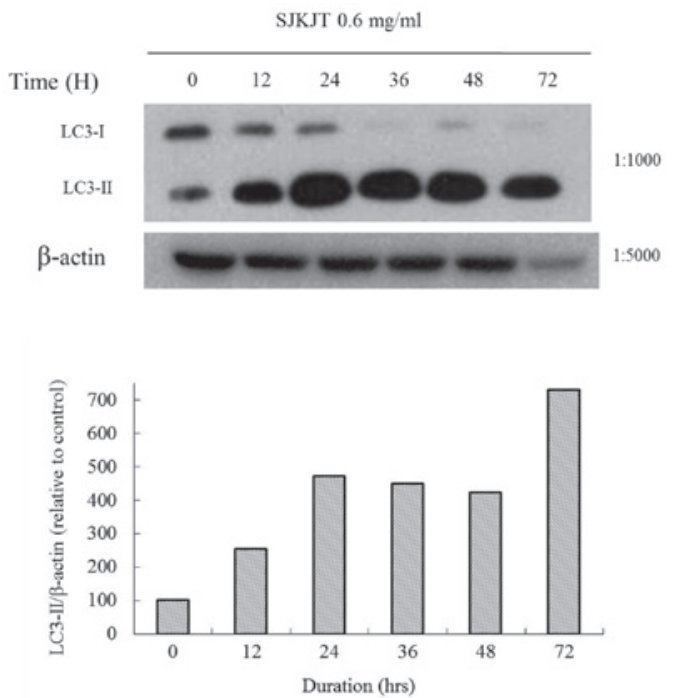

Figure 7. Protein expression of LC3-II in BxPC-3 cells. BxPC-3 cells were treated with SJKJT $(0.6 \mathrm{mg} / \mathrm{ml})$ for different durations $(0,12,24,36,48$ and $72 \mathrm{~h}$ ). Expression of the LC3-II protein was evaluated by western blot analysis. When BxPC-3 cells were treated with SJKJT for different durations, the expression of the LC3-II protein increased in a time-dependent manner. LC3-II, microtubule-associated protein II light chain 3; SJKJT, Sann-Joong-Kuey-Jian-Tang.
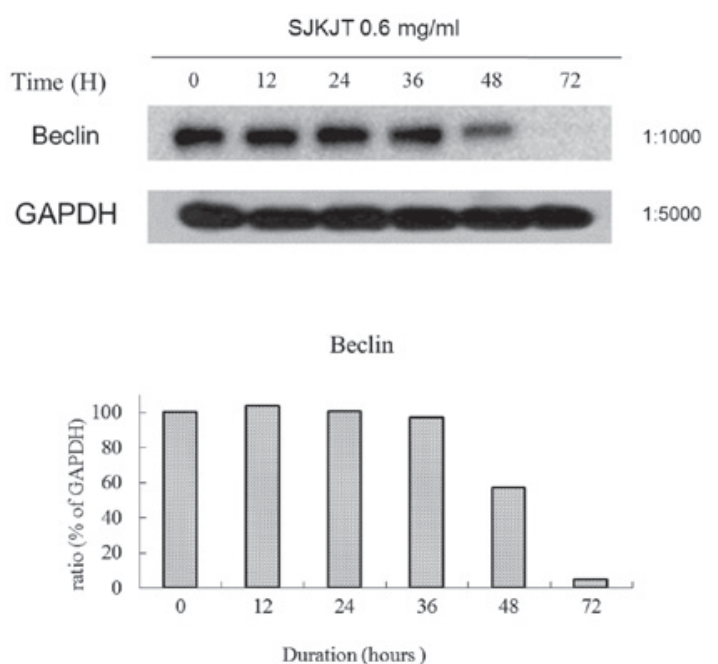

Figure 8. Protein expression of beclin-1 in BxPC-3 cells. BxPC-3 cells were treated with SJKJT $(0.6 \mathrm{mg} / \mathrm{ml})$ for different durations $(0,12,24,36,48$ and $72 \mathrm{~h}$ ). Expression of the beclin-1 protein was evaluated by western blot analysis The reference protein GAPDH was used as internal control. When BxPC-3 cells were treated with SJKJT for different durations, the expression of the beclin-1 protein was decreased at 48 and 72 h. Sann-Joong-Kuey-Jian-Tang.

Statistical analysis. Data are presented as the mean \pm standard deviation. Student's t-test was used to analyze statistical significance. $\mathrm{P}<0.05$ was considered indicate a statistically significant difference.

\section{Results}

Cytotoxicity of SJKJT to BxPC-3 cells. The results showed that SJKJT inhibits the proliferation of BxPC-3 cells. When cultured with various concentrations of SJKJT $(0$, $0.1,0.2,0.4,0.6,0.8$ and $1 \mathrm{mg} / \mathrm{ml}$ ) for 24,48 and $72 \mathrm{~h}$, the 
A

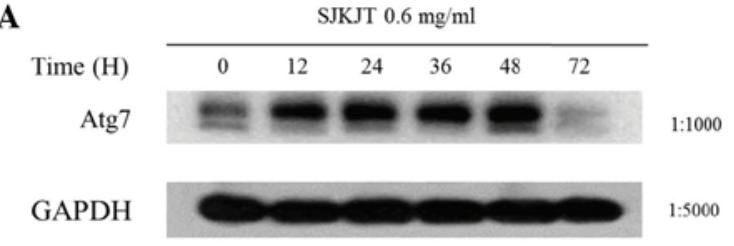

Atg7

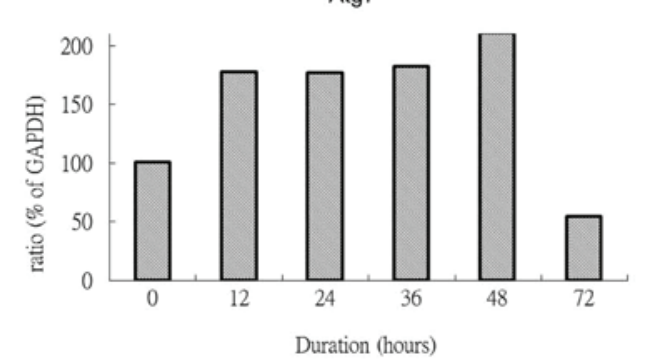

B

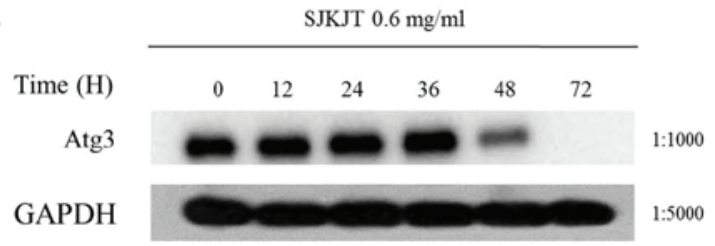

Atg3

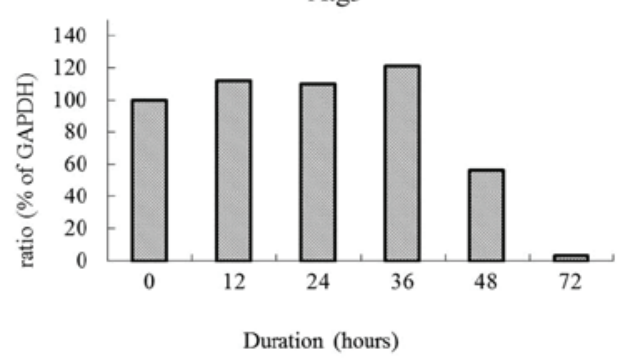

C
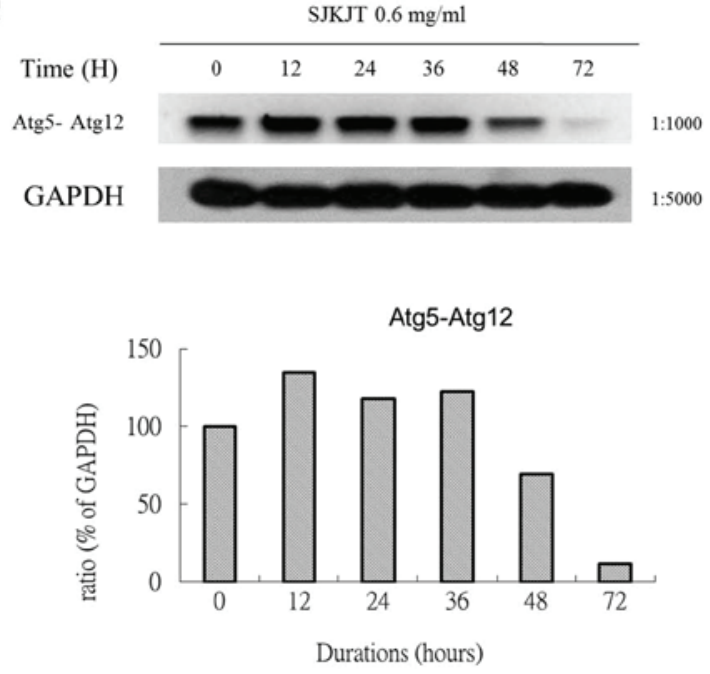

Figure 9. Protein expression of Atg7, Atg3 and Atg5-Atg12 in BxPC-3 cells. BxPC-3 cells were treated with SJKJT $(0.6 \mathrm{mg} / \mathrm{ml})$ for different durations $(0,12,24,36,48$ and $72 \mathrm{~h})$. Expression of these proteins was evaluated by western blot analysis. The reference protein GAPDH was used as internal control. (A) When BxPC-3 cells were treated with SJKJT for different durations the expression of the Atg7 protein increased during the first 12 to $48 \mathrm{~h}$, but decreased at $72 \mathrm{~h}$. (B) The expression of the Atg3 protein increased during the first 12 to $36 \mathrm{~h}$, but decreased at 48 to $72 \mathrm{~h}$. (C) The expression of the Atg5-Atg12 protein increased during the first 12 to $36 \mathrm{~h}$, but decreased at 48 to $72 \mathrm{~h}$. Atg, autophagocytosis-associated protein; SJKJT, Sann-Joong-Kuey-Jian-Tang.
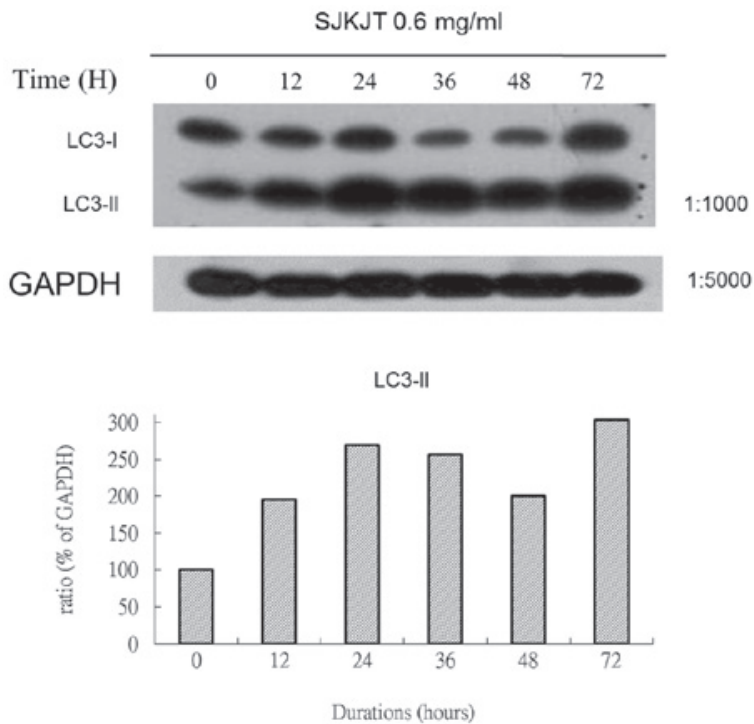

Figure 10. Protein expression of LC3-II in BxPC-3 cells. BxPC-3 cells were treated with SJKJT $(0.6 \mathrm{mg} / \mathrm{ml})$ for different durations $(0,12,24,36$, 48 and $72 \mathrm{~h}$ ). Expression of the LC3-II protein was evaluated by western blot analysis. The reference protein GAPDH was used as an internal control. When BxPC-3 cells were treated with SJKJT for different durations, the expression of the LC3-II protein increased in a time-dependent manner. LC3-II, microtubule-associated protein II light chain 3; SJKJT, Sann-Joong-Kuey-Jian-Tang.

percentages of viable cells relative to those of the control were $95.91 \pm 5.23,91.05 \pm 5.72,79.69 \pm 7.08,77.18 \pm 4.33,64.35 \pm 4.52$ and $60.03 \pm 4.16 \%$ at $24 \mathrm{~h} ; 78.56 \pm 8.72,72.59 \pm 6.48,62.83 \pm 4.53$, $52.17 \pm 3.98,44.49 \pm 4.31$ and $37.48 \pm 4.64 \%$ at $48 \mathrm{~h}$; and $65.54 \pm 4.74,56.92 \pm 2.52,40.94 \pm 4.41,31.10 \pm 4.98,26.51 \pm 4.20$ and $34.34 \pm 4.76 \%$ at $72 \mathrm{~h}$, respectively (Fig. 1). The results demonstrated that SJKJT inhibited the proliferation of human pancreatic cancer BxPC-3 cells in a time- and dose-dependent manner.

Expression of mTOR, beclin-1, Atg7, Atg3, Atg5-12 and LC3-II proteins in $\mathrm{BxPC}-3$ cells treated with SJKJT. BxPC-3 cells were treated with various concentrations $(0,0.3,0.6$ and $1.2 \mathrm{mg} / \mathrm{ml})$ of SJKJT for 48 or $72 \mathrm{~h}$ and the expression of beclin-1, Atg7, Atg3, Atg5-12 and LC3-II proteins was evaluated using western blot analysis. The results showed that when BxPC-3 cells were treated with various concentrations of SJKJT for 48 or $72 \mathrm{~h}$, the expression levels of the mTOR (Fig. 2), beclin-1 (Fig. 3), Atg7 (Fig. 4A), Atg3 (Fig. 4B) and Atg5-12 (Fig. 4C) proteins were decreased.

BxPC-3 cells were also treated with SJKJT $(0.6 \mathrm{mg} / \mathrm{ml})$ for different durations $(0,12,24,36,48$ and $72 \mathrm{~h})$ and the expression levels of mTOR, beclin-1, Atg7, Atg3, Atg5-12 and LC3-II proteins were evaluated by western blotting. The results obtained using different reference proteins (GAPDH or $\beta$-actin) provided similar results. The results demonstrated that when BxPC-3 cells were treated with SJKJT for different durations, the expressions of the beclin-1 (Figs. 5 and 8), Atg7 (Figs. 6A and 9A), Atg3 (Figs. 6B and 9B) and Atg5-12 (Figs. 6C and 9C) proteins were increased during the first $24 \mathrm{~h}$, but decreased at 48 and $72 \mathrm{~h}$. By contrast, the expression of the LC3-II protein increased in a time-dependent manner (Figs. 7 and 10). 


\section{Discussion}

Autophagy is one of forms of programmed cell death (type II cell death) (13). LC3-II levels may be used as a marker of autophagy and monitored using western blot analysis (14-15). When cellular stress leads to a continuous or excessive induction of autophagy, cell death may ensue (9). It has been shown that autophagy is activated in pancreatic cancer cells and is correlated with poor patient outcome (10). Yang et al (11) also demonstrated that pancreatic cancers require autophagy for tumor growth. The results of the present study showed that SJKJT inhibited the proliferation of BxPC-3 cells in a time- and dose-dependent manner in vitro. The results also demonstrated that when BxPC-3 cells were treated with various concentrations of SJKJT for 48 or $72 \mathrm{~h}$, the expression levels of the MTOR protein were decreased. When BxPC-3 cells were treated with SJKJT for varying durations, the expression of the LC3-II protein was increased in a time- and dose-dependent manner. Autophagy has been proposed as a novel target for anticancer therapy (16). A possible molecular mechanism underlying the inhibition of BxPC-3 human pancreatic cancer cells by SJKJT may proceed via reduction in the expression of mTOR, thereby leading to activation of autophagy in vitro. To the best of our knowledge, the present study was the first to demonstrate that SJKJT decreased the protein expression of mTOR but increased that of LC3-II, which was associated with the inhibition of BxPC-3 human pancreatic carcinoma cells. The therapeutic potential of SJKJT in human pancreatic cancer requires further investigation.

\section{Acknowledgements}

This study was supported by the Changhua Christian Hospital (grant no. 100-CCH-ICO-06-1).

\section{References}

1. Yang CH and Craise LM: Development of human epithelial cell systems for radiation risk assessment. Adv Space Res 14: $115-120,1994$.
2. Cheng CY, Lin YH and Su CC: Sann-Joong-Kuey-Jian-Tang up-regulates the protein expression of Fas and TNF- $\alpha$ in colo 205 cells in vivo and in vitro. Mol Med Rep 3: 63-67, 2010.

3. Chen YL, Yan MY, Chien SY, Kuo SJ, Chen DR, Cheng CY and Su CC: Sann-Joong-Kuey-Jian-Tang inhibits hepatocellular carcinoma Hep-G2 cell proliferation by increasing TNF- $\alpha$, Caspase- 8 , Caspase- 3 and Bax but by decreasing TCTP and Mcl-1 expression in vitro. Mol Med Rep 7: 1487-1493, 2013.

4. Siegel R, Ward E, Brawley O and Jemal A: Cancer statistics, 2011: the impact of eliminating socioeconomic and racial disparities on premature cancer deaths. CA Cancer J Clin 61:212-236, 2011.

5. Siegel R, Naishadham D and Jemal A: Cancer statistics, 2012: CA Cancer J Clin. 62: 10-29, 2012.

6. Mujumdar N, Mackenzie TN, Dudeja V, et al: Triptolide induces cell death in pancreatic cancer cells by apoptotic and autophagic pathways. Gastroenterology 139: 598-608, 2010.

7. Verhoef MJ, Balneaves LG, Boon HS and Vroegindewey A: Reasons for and characteristics associated with complementary and alternative medicine use among adult cancer patients: a systematic review. Integr Cancer Ther 4: 274-286, 2005.

8. Chien SY, Kuo SJ, Chen DR and Su CC: Sann-Joong-Kuey-Jian-Tang decreases the protein expression of Mcl-1 and TCTP and increases that of TNF- $\alpha$ and Bax in BxPC-3 pancreatic carcinoma cells. Int J Mol Med 32: 85-92, 2013.

9. Dalby KN, Tekedereli I, Lopez-Berestein G and Ozpolat B: Targeting the prodeath and prosurvival functions of autophagy as novel therapeutic strategies in cancer. Autophagy 6: 322-329, 2010.

10. Fujii S, Mitsunaga S, Yamazaki M, et al: Autophagy is activated in pancreatic cancer cells and correlates with poor patient outcome. Cancer Sci 99: 1813-1819, 2008.

11. Yang S, Wang X, Contino G, et al: Pancreatic cancers require autophagy for tumor growth. Genes Dev 25: 717-729, 2011.

12. Cheng CY, Lin YH and Su CC: Sann-Joong-Kuey-Jian-Tang increases the protein expression of microtubule-associated protein II light chain 3 in human colon cancer colo 205 cells. Mol Med Rep 2: 707-711, 2009.

13. Clarke PG: Developmental cell death: morphological diversity and multiple mechanisms. Anat Embryol (Berl) 181: 195-213, 1990.

14. Yang YP, Liang ZQ, Gu ZL and Qin ZH: Molecular mechanism and regulation of autophagy. Acta Pharmacol Sin 26: 1421-1434, 2005.

15. Konado Y and Kondo S: Autophagy and cancer therapy. Autophagy 2: 85-90, 2006.

16. Moretti L, Yang ES, Kim KW and Lu B: Autophagy signaling in cancer and its potential as novel target to improve anticancer therapy. Drug Resist Updat 10: 135-143, 2007. 